Research Paper

\title{
Increase of Soluble Programmed Cell Death Ligand 1 in Patients with Chronic Hepatitis C
}

\author{
Satoshi Yamagiwa ${ }^{1}$, Toru Ishikawa ${ }^{2}$, Nobuo Waguri ${ }^{3}$, Soichi Sugitani ${ }^{4}$, Kenya Kamimura ${ }^{1}$, Atsunori \\ Tsuchiya ${ }^{1}$, Masaaki Takamura ${ }^{1}$, Hirokazu Kawai ${ }^{1}$, Shuji Terai ${ }^{1}$
}

1. Division of Gastroenterology and Hepatology, Niigata University Graduate School of Medical and Dental Sciences, Niigata 951-8510, Japan;

2. Department of Gastroenterology and Hepatology, Saiseikai Niigata Daini Hospital, Niigata 950-1104, Japan

3. Department of Gastroenterology and Hepatology, Niigata City General Hospital, Niigata 950-1197, Japan;

4. Department of Gastroenterology and Hepatology, Tachikawa General Hospital, Nagaoka 940-8621, Japan.

$\square$ Corresponding author: Satoshi Yamagiwa, M.D., Ph.D. Division of Gastroenterology and Hepatology, Niigata University Graduate School of Medical and Dental Sciences, 1-757 Asahimachi-dori, Chuo-ku, Niigata 951-8510, Japan E-mail address: syamagi@med.niigata-u.ac.jp Telephone: +81-25-227-2207 Fax: $+81-25-227-0776$

(c) Ivyspring International Publisher. This is an open access article distributed under the terms of the Creative Commons Attribution (CC BY-NC) license (https://creativecommons.org/licenses/by-nc/4.0/). See http://ivyspring.com/terms for full terms and conditions.

Received: 2016.12.16; Accepted: 2017.03.01; Published: 2017.04.08

\begin{abstract}
Objectives: To determine whether the soluble programmed cell death ligand 1 (sPD-LI) levels in patients with chronic hepatitis $\mathrm{C}(\mathrm{CHC})$ are associated with the clinical features of the disease and the efficacy of treatment, including interferon (IFN)- $\alpha$.

Methods: We investigated the sPD-LI levels in the sera of 80 genotype $1 \mathrm{~b}$ Japanese patients with $\mathrm{CHC}$ who underwent 12 weeks of telaprevir (TVR)- or simeprevir (SMV)-based triple therapy followed by 12 weeks of dual therapy with pegylated IFN- $\alpha$ plus ribavirin. Serum was also obtained from 22 patients with chronic hepatitis $B(C H B)$ and from 10 healthy donors $(\mathrm{HC})$. The sPD-LI levels were measured using an ELISA kit. In addition, we examined the PD-LI expression on the cell surface of immortalized hepatocytes (HPTI) after incubation with cytokines, including IFN-y.

Results: The pretreatment serum sPD-L1 levels were significantly increased in patients with $\mathrm{CHC}$ (median $109.3 \mathrm{pg} / \mathrm{ml}$, range 23.1-402.3) compared with patients with CHB $(69.2 \mathrm{pg} / \mathrm{ml}, 15.5-144.8$; $P<0.001)$ and $\mathrm{HC}(100.3 \mathrm{pg} / \mathrm{ml}, 40.1-166.6 ; P=0.039)$. No significant differences in the sustained virological response (SVR) rates were found between the TVR- $(85.0 \%, n=40)$ and SMV-treated $(80.0 \%, n=40)$ groups, and the pretreatment levels of serum sPD-LI were not significantly different between patients who achieved SVR $(105.0 \mathrm{pg} / \mathrm{ml}, 23.1-402.3)$ and non-SVR patients $(133.5 \mathrm{pg} / \mathrm{ml}$, 39.9-187.2; $P=0.391)$. The pretreatment level of $s P D-L 1$ was positively correlated with the alanine aminotransferase and alpha-fetoprotein levels $\left(R^{2}=0.082, P=0.016\right.$, and $R^{2}=0.149, P=0.002$, respectively). Although immortalized hepatocytes do not express PD-LI, we confirmed that PD-LI expression was induced after stimulation with IFN-y.

Conclusions: In this study, we first found that SPD-LI was increased in patients with CHC. Our results indicate that the level of serum SPD-LI might be associated with the progression of $\mathrm{CHC}$ and the generation of hepatocellular carcinoma.
\end{abstract}

Key words: soluble programmed cell death ligand 1; programmed cell death 1; chronic hepatitis C; Telaprevir; Simeprevir.

\section{Introduction}

Chronic hepatitis $\mathrm{C}$ virus (HCV) infections affect approximately 130-170 million people worldwide and are associated with a greatly increased risk of developing liver cirrhosis and hepatocellular carcinoma (HCC) $[1,2]$. Dysfunction of virus-specific
$\mathrm{CD}^{+}$cells was demonstrated to be a fundamental property of persistent viral infections, such as HCV [3, 4]. In chronic viral infection, the persistent exposure to high concentrations of viral antigens leads to various degrees of T-cell functional impairments called T-cell 
exhaustion [5-7]. Previous studies have indicated that the interaction between programmed cell death-1 (PD-1) and its ligands plays a critical role in T-cell exhaustion [8]. PD-1 has been shown to be upregulated in $\mathrm{HCV}$-specific $\mathrm{CD}^{+}$cells, indicating that PD-1 upregulation may be an essential mechanism for viral immune escape in chronic $\mathrm{HCV}$ infections [9-11].

PD-1 is a key immune-checkpoint receptor expressed by activated T cells, B cells, and myeloid cells, and it delivers inhibitory signals by interacting with its two major ligands: programmed cell death ligand-1 (PD-L1) and -2 (PD-L2) [12]. PD-L1 (B7-H1) is largely expressed in both hematopoietic and parenchymal cells, and PD-L2 (B7-DC) is mainly expressed in macrophages and dendritic cells [13]. In tumor tissues, activated $\mathrm{T}$ cells can encounter the immunosuppressive PD-L1 and PD-L2, and both ligands are expressed by tumor cells and microenvironment, as described for lymphoproliferative diseases [14]. Recent studies have shown that antibody-mediated interference with PD-1 caused the regression of several tumor types, including melanoma, renal cell carcinoma (RCC), and non-small cell lung cancer, in some patients [3]. The expression of PD-L1 is induced by inflammatory cytokines, such as interferon (IFN)- $\gamma$ or interleukin-10 [16]. Moreover, it has been shown that a soluble form of PD-L1 (sPD-L1) can be detected in the sera of patients, which correlates with the amount of PD-L1 expressing cells [16].

An increase of sPD-L1 was reported in patients with malignancies, including multiple myeloma (MM) [17], RCC [18], and diffuse large B-cell lymphoma (DLBCL) [12]. Moreover, a recent study showed that a high sPD-L1 level was a possible prognostic indicator for a poor outcome in hepatocellular carcinoma (HCC) patients [15]. Although the PD-1/PD-L1 inhibitory pathway was shown to be associated with the T-cell dysfunction seen in chronic HCV infection [3], the involvement of sPD-L1 in the immunopathogenesis of $\mathrm{CHC}$ has yet to be determined. Therefore, we hypothesized that the level of sPD-L1 might be associated with clinical features, such as the severity of inflammation, the progression of fibrosis, carcinogenesis, and especially the efficacy of treatment including IFN- $\alpha$, which has been shown to induce the expression of PD-L1, in patients with $\mathrm{CHC}$.

Before the introduction of direct-acting antiviral agents (DAA), pegylated IFN (PegIFN)- $\alpha$ and ribavirin (RBV) were the standard treatments for $\mathrm{HCV}$ genotype 1 infections. However, with the approval of telaprevir (TVR), an HCV non-structural 3/4A (NS3/4A) protease inhibitor, the TVR-based triple therapy has led to an improved sustained virological response (SVR) rate compared with PegIFN-a monotherapy and PegIFN-a plus RBV dual therapy $[19,20]$. However, the TVR-based triple therapy is associated with an increased severity and rate of adverse events, including skin rash, pruritus, anemia, and anorectal diseases [20, 21]. Simeprevir (SMV) is a second-generation oral HCV NS3/4A protease inhibitor with antiviral activity against $\mathrm{HCV}$ genotype 1, 2, 4, 5, and 6 infections [22]. The SMV-based triple therapy showed a favorable efficacy without inducing severe dermatologic and hematologic toxicities [23]. In the present study, we aimed to determine whether the sPD-L1 levels in patients with CHC were associated with clinical features of the disease and the efficacy of TVR- and SMV-based triple therapies, including IFN-a. Moreover, the expression of PD-L1 in hepatocytes was examined after stimulation with IFN- $\gamma$.

\section{Methods}

\section{Patients}

This study enrolled two groups of $40 \mathrm{HCV}$ genotype $1 \mathrm{~b}$ Japanese patients who received 12 weeks of TVR-based or SMV-based triple therapies, followed by a 12 -week dual therapy that included PegIFN-a and RBV. The median age was 63 years (range: $28-84$ years). Twenty-two patients with chronic hepatitis B (CHB) (11 male and 11 female, median age 57 (30-76) years) and 10 healthy donors ( 5 male and 5 female, median age 64 (50-71) years) were used as controls. Serum samples were collected from each patient or healthy donor.

According to the prior treatment response, relapse was defined as undetectable HCV during and at the end of treatment, with HCV RNA positivity occurring later. A non-responder was defined as detectable HCV RNA for more than 24 weeks. Patients with decompensated liver cirrhosis, HCC, co-infection with hepatitis B virus or human immunodeficiency virus, autoimmune hepatitis, primary biliary cholangitis, hemochromatosis, or Wilson's disease were excluded from the study. Patients with uncontrollable hypertension or diabetes mellitus, chronic renal failure, depression, and those with a history of alcohol abuse, were also excluded. Information regarding the patient profiles is shown in Tables 1 and 2.

\section{Study design}

All patients received a 12-week triple therapy that included either TVR [1500 or $2250 \mathrm{mg} /$ day; the initial dose of TVR was determined by each attending physician based on each patient's baseline characteristics such as bodyweight (BW)] (Telavic; 
Mitsubishi Tanabe Pharma, Osaka, Japan) or SMV (100 mg/day) (Sovriad; Janssen Pharmaceutical K.K., Tokyo, Japan) combined with PegIFN-a2a (180 $\mu \mathrm{g} /$ week) (Pegasys; Chugai Pharmaceutical Co., Ltd., Tokyo, Japan) or PegIFN-a2b (1.5 $\mathrm{\mu g} / \mathrm{BW} \mathrm{kg} /$ week) (Peg-Intron; MSD, Tokyo, Japan) and RBV (600-1000 $\mathrm{mg} /$ day according to BW as follows: $<60 \mathrm{~kg}$ : 600 $\mathrm{mg} /$ day; $60-80 \mathrm{~kg}: 800 \mathrm{mg} /$ day; and $>80 \mathrm{~kg}: 1000$ $\mathrm{mg} /$ day; if the patient's hemoglobin was $<13 \mathrm{~g} / \mathrm{dL}$ at the start of therapy, RBV was reduced by $200 \mathrm{mg}$ ) (Copegus; Chugai Pharmaceutical Co., Ltd. or Rebetol; MSD) and followed by a 12-week dual therapy that included PegIFN-a2a or PegIFN- $a 2 b$ and RBV.

Table 1. Patient characteristics

\begin{tabular}{|c|c|c|c|}
\hline Factors (Median, range) & Healthy Control & $\mathrm{CHB}$ & $\mathrm{CHC}$ \\
\hline $\mathrm{n}$ & 10 & 22 & 80 \\
\hline Gender, n (Male / Female) & $5 / 5$ & $11 / 11$ & $41 / 39$ \\
\hline Age (years) & $64(50-71)$ & $57(30-76)$ & $63(28-84)$ \\
\hline Albumin (mg/dL) & $4.3(3.3-5.0)$ & $4.4(3.2-4.9)$ & $4.1(2.8-5.9)$ \\
\hline AST (IU/L) & $21(16-30)$ & $23(16-199)$ & $39(20-200)^{*}$ \\
\hline ALT (IU/L) & $13(3-18)$ & $23(10-336)^{* *}$ & $40(14-316)^{*}$ \\
\hline Platelets $\left(\times 10^{4} / \mathrm{mm}^{3}\right)$ & $18.4(12.9-22.7)$ & $18.6(9.9-28.4)$ & $15.6(7.4-31.7)$ \\
\hline Alpha-fetoprotein (ng/mL) & - & $3.0(1.0-9.9)$ & $4.3(1.1-258.0)^{\dagger}$ \\
\hline HCV-RNA (log IU/mL) & - & - & $6.7(4.7-7.8)$ \\
\hline HBV-DNA (log copies/mL) & - & $4.5(0-8.6)$ & - \\
\hline $\begin{array}{l}\text { Nucleoside analogue, n (- / } \\
+ \text { ) }\end{array}$ & & $19 / 3$ & - \\
\hline
\end{tabular}

Table 2. Patient characteristics ( $\mathrm{CHC})$

\begin{tabular}{|c|c|c|c|}
\hline Factors (Median, range) & Telaprevir & Simeprevir & $P$ value \\
\hline $\mathrm{n}$ & 40 & 40 & - \\
\hline Gender, n (Male / Female) & $23 / 17$ & $18 / 22$ & 0.371 \\
\hline Age (years) & $62(28-77)$ & $65(36-84)$ & 0.253 \\
\hline Body weight (kg) & $59.2(40.0-97.4)$ & $58.6(37.5-83.7)$ & 0.593 \\
\hline Body mass index $\left(\mathrm{kg} / \mathrm{m}^{2}\right)$ & $23.0(15.8-32.2)$ & $22.8(17.8-28.6)$ & 0.951 \\
\hline $\begin{array}{l}\text { Baseline HCV-RNA (log } \\
\mathrm{IU} / \mathrm{mL} \text { ) }\end{array}$ & $6.7(5.4-7.8)$ & $6.7(4.7-7.8)$ & 0.129 \\
\hline White blood cell $\left(/ \mathrm{mm}^{3}\right)$ & $5150(1900-8400)$ & $4525(2600-7500)$ & 0.112 \\
\hline Hemoglobin (g/dL) & $14.2(10.9-18.6)$ & $13.5(10.0-16.7)$ & 0.034 \\
\hline Platelets $\left(\times 10^{4} / \mathrm{mm}^{3}\right)$ & $14.9(7.4-24.0)$ & $16.3(8.7-31.7)$ & 0.080 \\
\hline Albumin (mg/dL) & $4.1(3.4-5.9)$ & $4.1(2.8-4.8)$ & 0.899 \\
\hline AST (IU/L) & $40(17-249)$ & $38(20-159)$ & 0.221 \\
\hline ALT (IU/L) & $40(18-278)$ & $41(14-316)$ & 0.362 \\
\hline GGT (IU/L) & $31(11-418)$ & $27(9-260)$ & 0.394 \\
\hline Serum creatinine (mg/dL) & $0.74(0.36-1.16)$ & $0.69(0.43-1.36)$ & 0.181 \\
\hline Estimated GFR (mL/min) & $77.0(44.0-134.0)$ & $80.5(41.3-112.6)$ & 0.912 \\
\hline Alpha-fetoprotein (ng/mL) & $4.4(1.1-144.9)$ & $4.1(1.2-258.0)$ & 0.768 \\
\hline $\begin{array}{l}\text { Prior treatment response, } \mathrm{n} \\
\text { (naïve / relapse / } \\
\text { non-responder) }\end{array}$ & $19 / 17 / 4$ & $21 / 13 / 6$ & 0.574 \\
\hline $\begin{array}{l}\text { IL28B SNP (rs8099917), n (TT / } \\
\text { non-TT / ND) }\end{array}$ & $24 / 15 / 1$ & $24 / 14 / 2$ & 1 \\
\hline
\end{tabular}

This study was conducted in accordance with the Declaration of Helsinki. The study was reviewed and approved by the Niigata University Medical and Dental Hospital Institutional Review Board. Written informed consent was obtained from all of the individuals who enrolled in the study according to the institutional review board's approved protocols (approval no. 1474) at the Niigata University Medical and Dental Hospital.

\section{Laboratory and safety assessments}

Laboratory and safety assessments were performed at treatment initiation; at treatment weeks $2,4,8,12,16,20$, and 24; at the end of treatment; and at 12 and 24 weeks after the end of treatment. Data on adverse events were collected, and physical examinations were performed at each visit if they were clinically indicated.

\section{Determination of HCV markers}

The baseline and follow-up tests for $\mathrm{HCV}$ viremia were performed using a real-time polymerase chain reaction (PCR) assay (COBAS TaqMan HCV test, Roche Diagnostic, Tokyo, Japan) with a lower limit of quantitation of $15 \mathrm{IU} / \mathrm{mL}$ and a linear dynamic range of 1.2-7.8 log IU $/ \mathrm{mL}$. The core amino acid substitutions at positions 70 and 91 of the HCV genome were determined by direct sequencing, as reported previously [24].

\section{Efficacy of treatment}

Successful treatment was SVR, which was defined as undetectable serum HCV RNA 24 weeks after the end of treatment. Early virological response during the first 12 weeks of treatment was categorized as follows: rapid virological response (RVR), undetectable HCV RNA at week 4; complete early virological response (cEVR), undetectable at week 12 . The end of treatment response (ETR) was defined as undetectable HCV RNA at the end of treatment. Relapse was defined as a response that was an ETR but non-SVR.

\section{Interleukin 28B single-nucleotide polymorphism}

Human genomic DNA was extracted from the peripheral blood. Single-nucleotide polymorphism (SNP) genotyping of the interleukin 28B (IL28B) (rs8099917) gene was performed using the TaqMan Allelic Discrimination Demonstration Kit $(7500$ Real-time PCR System) (Applied Biosystems, Foster City, CA, USA). The rs8099917 genotype was classified into the following 2 categories: TT (major genotype) and non-TT (minor genotype, TG or GG). 


\section{Measurement of serum sPD-LI}

Serum levels of sPD-L1 were examined using a specific enzyme-linked immunosorbent assay (ELISA) kit from Cusabio Biotech (Wuhan, China) according to the manufacture's protocol. Each sample was tested in duplicate. The detection limits for ELISA was 3.9 $\mathrm{pg} / \mathrm{ml}$.

\section{Cell surface expression of PD-LI on human hepatocytes}

Immortalized human hepatocytes (HPT1) were kindly provided by Prof. T. Kanda at Chiba University, Chiba, Japan. Cell surface expression of PD-L1 was examined using flow cytometry before and after stimulation with IFN- $\gamma$. Cells $\left(10^{5}\right)$ were labeled with anti-PD-L1 (CD274)-PE and anti-MHC class I-FITC antibodies at $4^{\circ} \mathrm{C}$ for $30 \mathrm{~min}$ in darkness, and the cells were washed 2 times and measured with a FACS Calibur flow cytometer (Becton Dickinson, San Jose, CA, USA). Data were analyzed using Flow Jo software (Tree Star Inc., Ashland, OR, USA). Expression of the mRNA of PD-L1 was also examined with real-time qPCR.

\section{Statistical analysis}

Continuous data from patients are expressed as the median with the interquartile range. The significance of differences was analyzed statistically with the Chi-square, Fisher's exact test, or the Mann-Whitney U test, as appropriate, using SPSS software (Ver.18, SPSS Inc., Chicago, IL, USA). Correlations between parameters were determined by linear regression analysis. In all cases, the level of significance was set as $P<0.05$.

\section{Results}

\section{Patient characteristics}

The patient characteristics in the $\mathrm{CHC}, \mathrm{CHB}, \mathrm{HC}$, TVR, and SMV groups are summarized in Tables 1 and 2. The analysis of the pretreatment factors revealed that serum asparate aminotransferase (AST), alanine aminotransferase (ALT), and alpha-fetoprotein (AFP) in the patients with $\mathrm{CHC}$ were significantly high compared with $\mathrm{HC}$, although there were no significant differences in the serum ALT levels between the patients with $\mathrm{CHC}$ and $\mathrm{CHB}$ (Table 1). Among the patients with $\mathrm{CHC}$, the baseline hemoglobin level and the number of patients infected with $\mathrm{HCV}$ with a mutation at position 91 of the $\mathrm{HCV}$ core protein were significantly higher in the TVR group compared with the SMV group $(P=0.034$ and 0.012 , respectively), but there was no significant difference in the other examined factors between the TVR and SMV groups (Table 2).

\section{Treatment responses}

Treatment tolerability is summarized in Table 3. Adverse events resulted in treatment discontinuation in $20 \%$ (8/40 cases) and $2.5 \%$ (1/40 cases) of patients in the TVR and SMV groups, respectively $(P<0.001)$. Eight patients $(20 \%)$ discontinued TVR because of adverse events (four patients experienced skin rash, three patients experienced anemia, and one patient experienced renal dysfunction). Although the cumulative exposure to RBV for the whole 24-week treatment period (as a percentage of the target dose) was significantly lower in the TVR group than the SMV group $(75.9 \pm 24.7 \%$ vs. $92.1 \pm 28.0 \%, P=0.007)$, cEVR, ETR, and SVR did not significantly differ between the TVR and SMV groups $(92.5 \%$ vs. $97.5 \%$, $92.5 \%$ vs. $92.5 \%$, and $85.0 \%$ vs. $80.0 \%$, respectively) (Figure 1). The rate of patients achieving RVR was significantly lower in the TVR group than in the SMV group (60.0\%vs. $92.5 \%, P=0.001)$, but the lower RVR rate did not seem to affect the SVR rate.

(\%)

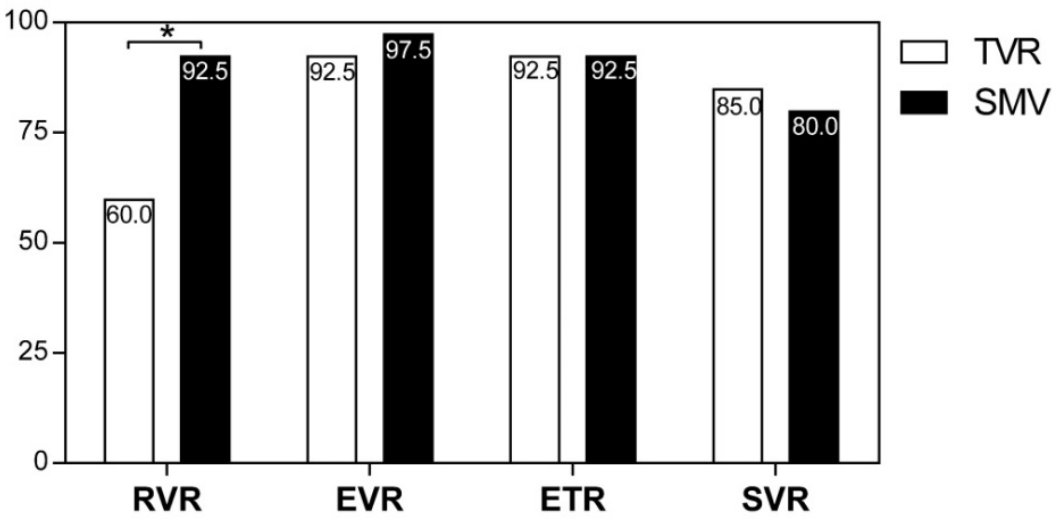

Figure 1. Rates of virological responses to telaprevir and simeprevir. Percentages indicate the proportion of patients with undetectable serum hepatitis C virus (HCV) RNA levels. RVR, rapid virological response; $c E V R$, complete early virological response; ETR, end of treatment response; SVR, sustained virological response defined as undetectable serum HCV RNA at 24 weeks after the end of treatment. $* P=0.001$. 


\section{Serum SPD-LI and correlation with clinical characteristics}

The pretreatment serum sPD-L1 levels were significantly increased in patients with $\mathrm{CHC}$ (median $109.3 \mathrm{pg} / \mathrm{ml}$, range 23.1-402.3) compared with patients with CHB $(69.2 \mathrm{pg} / \mathrm{ml}, 15.5-144.8 ; P<0.001)$ and $\mathrm{HC}(100.3 \mathrm{pg} / \mathrm{ml}, 40.1-166.6 ; P=0.039)$ (Figure 2). The pretreatment level of sPD-L1 was positively correlated with the AST and ALT levels in patients with CHC $\left(\mathrm{R}^{2}=0.066, P=0.032\right.$, and $\mathrm{R}^{2}=0.082, P=$ 0.016 , respectively) (Figure $3 \mathrm{AB}$ ). There was no significant correlation between serum sPD-L1 and platelet levels (Figure 3C), but serum SPD-L1 was also significantly correlated with the AFP levels $\left(\mathrm{R}^{2}=\right.$ 0.149, $P=0.002$ ) (Figure 3D). Although the pretreatment levels of serum sPD-L1 were not significantly different between the patients who achieved SVR (105.0 pg/ml, 23.1-402.3) and non-SVR $(133.5 \mathrm{pg} / \mathrm{ml}, 39.9-187.2)(P=0.391)$ (Figure 4), these results indicated a correlation between the severity of inflammation and sPD-L1 levels in patients with $\mathrm{CHC}$

\section{Induced expression of PD-LI on hepatocytes}

It has been demonstrated that the existence of sPD-L1 was associated with PD-L1 expression on the cell surface. To examine the expression of PD-L1 on the cell surface of hepatocytes, we used immortalized hepatocytes (HPT1) (Figure 5). The hepatocytes did not express PD-L1 without any stimulation. However, IFN- $\gamma$ clearly induced the expression of PD-L1 on the hepatocytes (Figure 5A). We also confirmed the induction of PD-L1 mRNA in the hepatocytes with
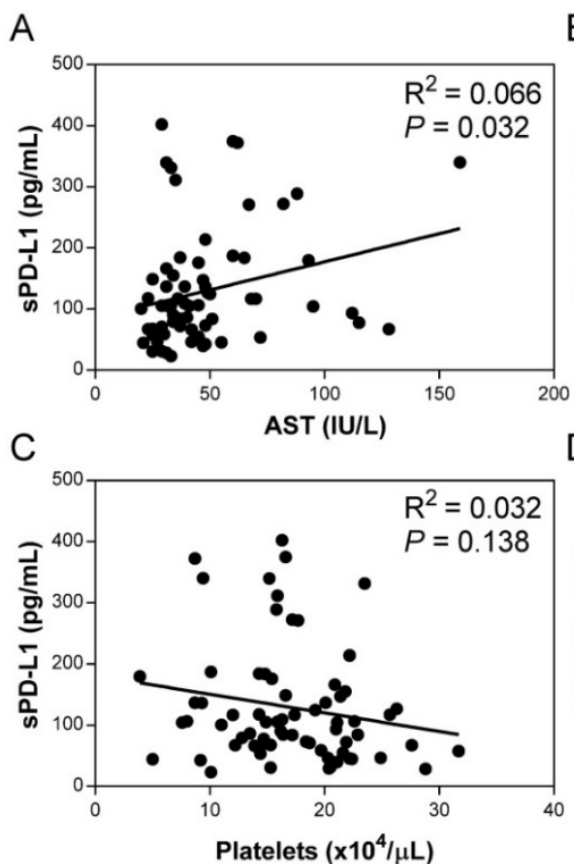

IFN- $\gamma$ (Figure 5B). Considering the significant positive correlation between the sPD-L1 and aminotransferase levels, these results revealed that SPD-L1 was released from the hepatocytes and that the increase in SPD-L1 resulted from the induction of PD-L1 expression on the hepatocytes due to inflammatory cytokines, including IFN- $\gamma$.

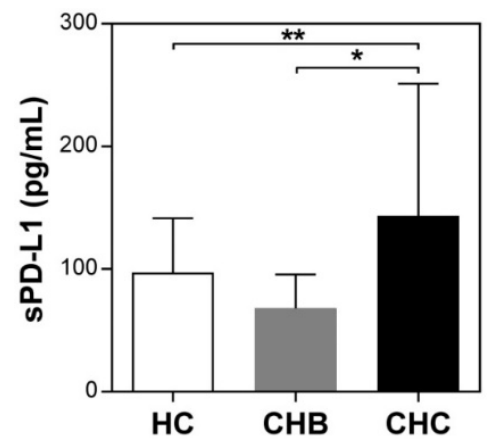

Figure 2. Serum sPD-L1 levels in patients with $\mathrm{CHC}, \mathrm{CHB}$, and healthy controls. Serum SPD-LI levels were examined using a specific enzyme-linked immunosorbent assay kit. Pretreatment levels of sPD-L1 in patients with $\mathrm{CHC}$ were compared with those in patients with $\mathrm{CHB}$ and healthy controls. $* P<0.001$, $* * P=0.039$.

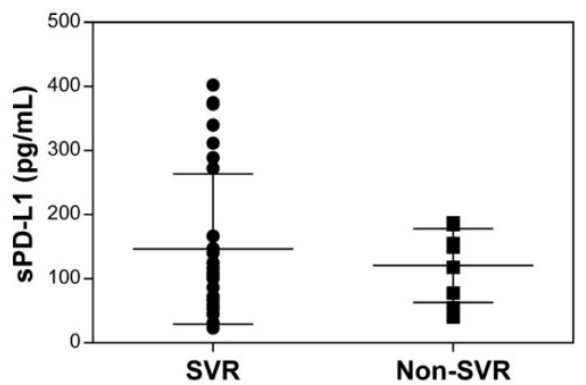

Figure 4. Comparison of pretreatment serum sPD-L1 levels between the patients who achieved SVR and non-SVR. The pretreatment levels of serum sPD-L1 were not significantly different between the patients who achieved SVR and non-SVR $(P=$ $0.391)$. SVR, sustained virological response.

$\mathrm{B}$

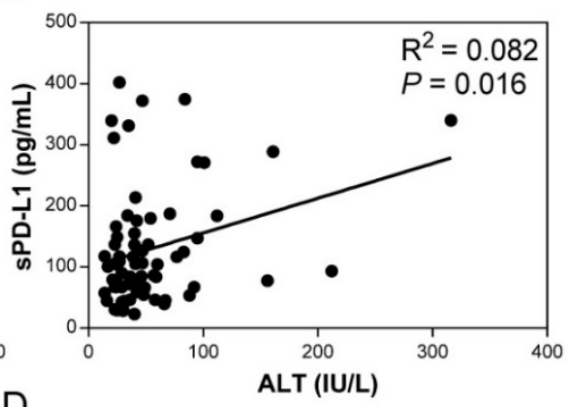

$\mathrm{D}$

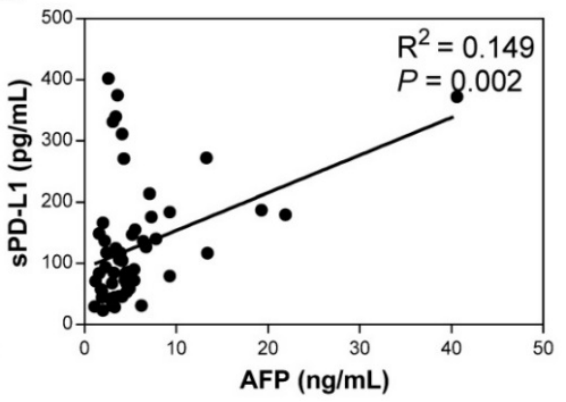

Figure 3. Correlation of serum sPD-L1 levels with asparate aminotransferase (AST) (A), alanine aminotransferase (ALT) (B), platelets (C), and alfa-fetoprotein (AFP) (D) in the patients with $\mathrm{CHC}$. Correlations between the serum sPD-LI and indicated parameters in patients with $\mathrm{CHC}$ were determined by linear regression analysis. 


\section{A}

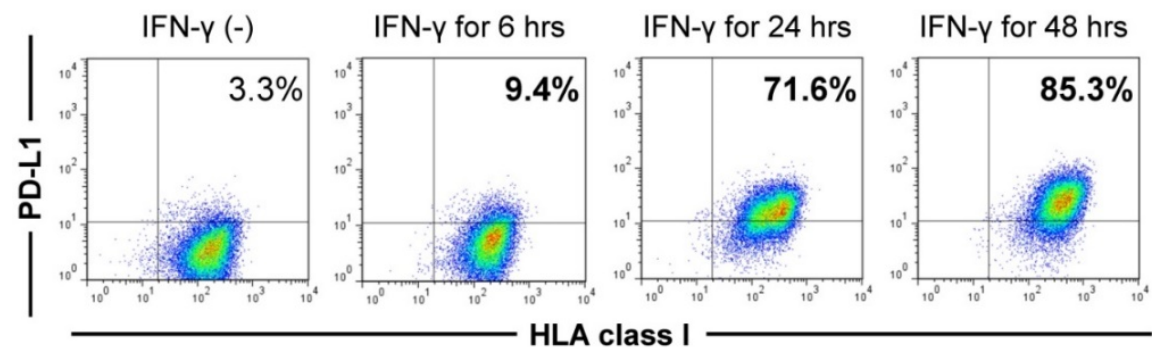

B

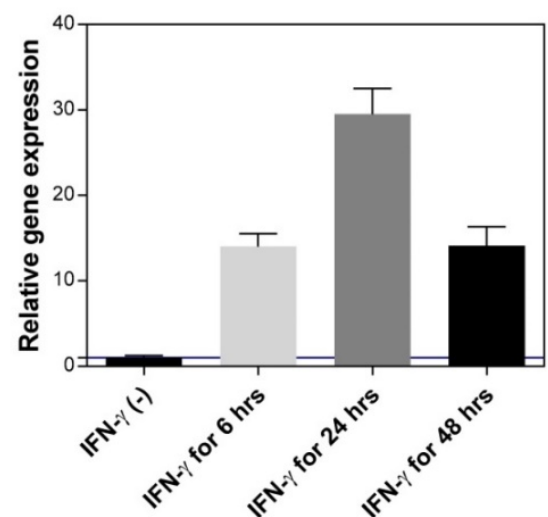

Figure 5. Expression of PD-L1 in immortalized hepatocytes. The expression of PD-L1 on the cell surface of immortalized hepatocytes (HPT1) was examined by flow cytometry before and after stimulation with IFN-Y (A). The expression of PD-LI mRNA was examined using real-time qPCR before and after stimulation with IFN-Y (B). HLA, human leukocyte antigen.

Table 3. Treatment tolerability

\begin{tabular}{|c|c|c|c|}
\hline & Telaprevir & Simeprevir & $P$ value \\
\hline $\mathrm{n}$ & 40 & 40 & - \\
\hline \multicolumn{4}{|l|}{ Initial doses (Median, range) } \\
\hline $\begin{array}{l}\text { PegIFN-a2a / BW } \\
(\mu \mathrm{g} / \mathrm{kg} / \text { week })\end{array}$ & & $3.10(2.15-4.25)$ & - \\
\hline $\begin{array}{l}\text { PegIFN-a2b / BW } \\
(\mu \mathrm{g} / \mathrm{kg} / \text { week })\end{array}$ & $1.50(0.92-2.00)$ & $1.51(1.19-2.67)$ & 0.070 \\
\hline TVR / BW (mg/kg/day) & 31.4 (17.3-56.3) & - & - \\
\hline SMV / BW (mg/kg/day) & - & $1.71(1.19-2.67)$ & - \\
\hline RBV / BW (mg/kg/day) & $11.6(6.9-20.0)$ & $11.6(6.0-16.8)$ & 0.749 \\
\hline \multicolumn{4}{|l|}{$\begin{array}{l}\text { Dose reduction / } \\
\text { Discontinuation, } \mathrm{n}\end{array}$} \\
\hline PegIFN-a & $2 / 6$ & $3 / 5$ & 1 \\
\hline TVR / SMV & $11 / 8$ & $0 / 1$ & $<0.001$ \\
\hline RBV & $24 / 6$ & $15 / 4$ & 0.039 \\
\hline \multicolumn{4}{|l|}{ Adherence, mean \pm SD (\%) } \\
\hline PegIFN- $\alpha$ & $92.1 \pm 21.2$ & $98.5 \pm 26.4$ & 0.235 \\
\hline TVR / SMV & $88.7 \pm 22.0$ & $95.3 \pm 22.5$ & 0.188 \\
\hline RBV & $75.9 \pm 24.7$ & $92.1 \pm 28.0$ & 0.007 \\
\hline
\end{tabular}

PegIFN, pegylated-interferon; BW, body weight; TVR, telaprevir; SMV, simeprevir; RBV, ribavirin

\section{Discussion}

In the present study, we investigated the sPD-L1 levels in the sera of 80 Japanese patients with chronic genotype $1 \mathrm{~b} \mathrm{HCV}$ infection. We found that the pretreatment sPD-L1 levels were significantly increased in patients with $\mathrm{CHC}$ compared with patients with $\mathrm{CHB}$ and healthy controls. To the best of our knowledge, this is the first study that revealed an increase in serum sPD-L1 in patients with $\mathrm{CHC}$, although high levels of sPD-L1 were reported in patients with HCC [15]. The expression of PD-L1 in tumor tissues has been reported to be of prognostic value in patients with HCC [25-27]. Finkelmeier et al. reported that HCC patients with high serum sPD-L1 concentrations had an increased mortality risk and that high sPD-L1 levels were associated with mortality independently from cirrhosis stage and AFP levels [15]. Although no significant correlation between the sPD-L1 levels and platelet counts was found in the present study, we found significant positive correlations between the level of serum sPD-L1 and the levels of AST, ALT and AFP in patients with $\mathrm{CHC}$. This positive correlation between sPD-L1 and AFP levels may suggest an association of sPD-L1 with the generation of HCC, but further investigation would be necessary to confirm that connection.

An increase of sPD-L1 was reported in patients with several malignant diseases, MM [17], RCC [18], and DLBCL [12]. Wang et al. reported that patients with MM had higher sPD-L1 concentration than healthy controls, and higher sPD-L1 levels were an 
independent prognostic factor for shorter progression-free survival [17]. In the patients with RCC, higher preoperative sPD-L1 levels were reported to be associated with lager tumors, tumors of advanced stage and grade, and tumors with necrosis [18]. Rossille et al. reported that among the patients with DLBCL, elevated SPD-L1 was associated with a poorer prognosis, and the sPD-L1 levels dropped back to a normal value after complete remission [12]. These reports may suggest that sPD-L1 could outline T-cell inhibitory signals and therefore mirror the anti-immune response of the diseases.

An increase in serum sPD-L1 was also reported in patients with non-malignant diseases such as systemic sclerosis [28] and type 2 diabetes mellitus (DM) [29]. Yanaba et al. reported that serum sPD-L1 levels positively correlated with the severity of skin sclerosis in the patients with systemic sclerosis [28]. Shi et al. reported that the levels of sPD-L1 in patients with type $2 \mathrm{DM}$ were higher compared with healthy donors and that the increase in SPD-L1 was closely associated with the severity of diabetic atherosclrelotic macorovasucular diseases, especially acute coronary syndrome [29]. Therefore, they speculated that SPD-L1 may contribute to continuous $\mathrm{T}$ cell activation and development of diabetic macrovascular diseases [29]. Abnormal increase of sPD-L1 may intervene in the PD-1/PD-L1 inhibitory pathway and participate in the chronic autoimmune response and pathological progress of inflammation [29]. Considering the positive correlation between the sPD-L1 and ALT levels, the increase of sPD-L1 may also contribute to T-cell activation in patients with $\mathrm{CHC}$, which results in an increase in the ALT levels.

We found that the expression of PD-L1 was induced on immortalized hepatocytes by IFN- $\gamma$, which was consistent with previous reports that describe how PD-L1was induced in primary human liver cells and hepatoma cells by viral infection and by IFN- $\alpha$ and $-\gamma[30]$. Mühlbauer et al. also reported that the PD-L1 expression on hepatocytes induced apoptosis in T cells by in vitro coculture of hepatocytes with $\mathrm{T}$ cells, and the authors speculated that the PD-L1 expression in hepatocytes may contribute to hepatic tolerance induction by deletion of activated $\mathrm{T}$ cells through the induction of apoptosis [30]. Although we did not examine the sPD-L1 in the supernatant of immortalized hepatocytes, Chen et al. reported that the existence of sPD-L1 was associated with PD-L1 expressed on the cell surface and that the release of sPD-L1 was, at least in part, associated with matrix metalloproteinase [16]. Therefore, we speculated that the increase of sPD-L1 in the patients with $\mathrm{CHC}$ might result from the induction of PD-L1 in hepatocytes due to inflammatory cytokines including,
IFN- $\gamma$.

Although there were no significant differences in the levels of serum ALT between the patients with $\mathrm{CHB}$ and $\mathrm{CHC}$, we found that the pretreatment sPD-L1 levels were significantly increased in patients with $\mathrm{CHC}$ compared with patients with $\mathrm{CHB}$. The reason the serum sPD-L1 levels differed between patients with $\mathrm{CHB}$ and $\mathrm{CHC}$ currently remains unclear, but we speculated that a different cytokine profile, mainly the level of IFN- $\gamma$, in the liver might result in the difference in the serum sPD-L1 levels between patients with $\mathrm{CHB}$ and $\mathrm{CHC}$. Bertoletti et al. compared the cytokine profiles of $\mathrm{T}$ cell clones derived from the liver infiltrates of patients with $\mathrm{CHB}$ and $\mathrm{CHC}$ and demonstrated that the predominant $\mathrm{T}$ cell population in $\mathrm{CHB}$ was represented by $\mathrm{T}$ helper (Th) 0 cells producing lower levels of IFN- $\gamma$ in addition to interleukin (IL)- 4 and IL-5. On the other hand, T cells with a Th1-like profile, able to secrete high amounts of IFN- $\gamma$, were enriched in the livers of patients with $\mathrm{CHC}$ [31]. The higher production of IFN- $\gamma$ in the livers of patients with $\mathrm{CHC}$ might account for the release of higher levels of sPD-L1 from hepatocytes compared with patients with CHB. Recently, unexpected early HCC recurrences in patients with HCV-related HCC undergoing IFN-free therapies has been reported [32]. Because IFN- $\gamma$ is mainly produced by natural killer cells and Th1 cells and participates principally in cell-mediated immunity [31], such early recurrence might result partly from decreased cell-mediated immunity caused by a decrease in Th1-type cytokine production, including IFN- $\gamma$, in the livers of patients with $\mathrm{CHC}$ after the eradication of HCV by IFN-free therapies.

The present study has a number of limitations. First, the sample size might have provided inadequate statistical power to detect definitive differences among the patients with $\mathrm{CHC}, \mathrm{CHB}$ and healthy controls, and between the SVR and no-SVR data in the patients with $\mathrm{CHC}$. Second, we examined only the pretreatment levels of sPD-L1 in patients with $\mathrm{CHC}$. Because we hypothesized that the efficacy of treatments, including IFN, might be more influenced by the sPD-L1 levels in patients with $\mathrm{CHC}$, we enrolled the patients treated with IFN-based treatments in the present study. Although we did not find a significant association between the sPD-L1 levels and the efficacy of treatments, it may be essential to evaluate the influence of treatment on the serum levels of sPD-L1. Third, we examined the serum levels of sPD-L1 in patients with $\mathrm{CHC}$, which was consistent with previous reports [15-18]. However, a recent report showed that sPD-L1 was more detectable in human plasma than in serum [12]. Rossille et al. speculated that serum might be less 
efficient for cytokine recovery [12]. Therefore, it would be worthwhile to examine sPD-L1 in the plasma of patients with CHC. However, measurements in cohorts of patients with $\mathrm{CHB}$ and healthy controls should eliminate this bias.

In conclusion, we first found that sPD-L1 was increased in the sera of patients with $\mathrm{CHC}$, although no association between the sPD-L1 levels and the efficacy of TVR- or SMV-based triple therapy was defined. Our results indicated that the level of serum sPD-L1 might be associated with the progression of $\mathrm{CHC}$ and the generation of hepatocellular carcinoma. Although the particular role of sPD-L1 requires further investigation, this study suggested that sPD-L1 might be involved in the immune pathogenesis of $\mathrm{CHC}$.

\section{Abbreviations}

CHC: chronic hepatitis C; sPD-L1: soluble programmed cell death 1; IFN: interferon; TVR: telaprevir; SMV: simeprevir; CHB: chronic hepatitis B; AST: asparate aminotransferase; ALT: alanine aminotransferase; AFP: alfa-fetoprotein; SVR: sustained virological response.

\section{Acknowledgement}

This word was supported by Grants-in-Aid for Scientific Research (C) (15K08991 to S.Y.) and (B) (26293175D to S.T.) from Japan Society for the Promotion of Science (JSPS) and the Project Promoting Clinical Trials for Development of New Drugs and Medical Devices (Japan Medical Association) (15bm05040003h0205 to S.T.) from Japan Agency for Medical Research and Development, AMED.

\section{Author contributions}

Yamagiwa S, Ishikawa T, Waguri $\mathrm{N}$ and Terai S contributed to study conception and design; Sugitani S, Kamimura K, Tsuchiya A, Takamura M, and Kawai $\mathrm{H}$ contributed to data acquisition, data analysis and interpretation; Yamagiwa $S$ and Terai $S$ contributed to drafting the article; all authors contributed to making critical revisions related to important intellectual content of the manuscript; all authors contributed to final approval of the version of the article to be published.

\section{Competing Interests}

The authors have declared that no competing interest exists.

\section{References}

1. Seeff LB, Buskell-Bales Z, Wright EC, Durako SJ, Alter HJ, Iber FL, et al. Long-Term Mortality after Transfusion-Associated Non-A, Non-B Hepatitis. N Engl J Med. 1992; 327: 1906-11.
2. Mohd Hanafiah K, Groeger J, Flaxman AD, Wiersma ST. Global epidemiology of hepatitis $C$ virus infection: new estimates of agespecific antibody to $\mathrm{HCV}$ seroprevalence. Hepatology. 2013; 57: 1333-42.

3. Salem ML, El-Badawy A. Programed death-1/programmed deth-L1 signaling pathway and its blockade in hepatitis C immunotherapy. World J Hepatol. 2015; 7: 2449-58.

4. Shin EC, Rehermann B. Taking the brake off $\mathrm{T}$ cells in chronic viral infection. Nat Med. 2006; 12: 276-7.

5. Cheng HY, Kang PJ, Chuang YH, Wang YH, Jan MC, Wu CF, et al. Circulating programmed death-1 as a marker for sustained high hepatitis B viral load and risk of hepatocellular carcinoma. PLoS One. 2014; 9: e95870.

6. Fisicaro P, Valdatta C, Mssari M, Loggi E, Biasini E, Sacchelli L, et al. Antiviral intrahepatic T-cell responses can be restored by blocking programmed death-1 pathway in chronic hepatitis B. Gastroenterology. 2010; 138: 682-93.

7. Raziorrouh B, Ulsenheimer A, Schraut W, Heeg M, Kurktschiev P, Zachoval R, et al. Inhibitory molecules that regulate expansion and restoration of $\mathrm{HCV}$-specific $\mathrm{CD}^{+} \mathrm{T}$ cells in patients with chronic infection. Gastroenterology. 2011; 141: 1422-31.

8. Barber DL, Wherry EJ, Masopust D, Zhu B, Allison JP, Sharpe AH, et al. Restoring function in exhausted CD8 T cells during chronic viral infection. Nature. 2006; 439: 682-7.

9. Radziewicz H, Ibegbu CC, Fernandez ML, Workowski KA, Obideen K, Wehbi $\mathrm{M}$, et al. Liver-infiltrating lymphocytes in chronic human hepatitis $C$ virus infection display an exhausted phenotype with high levels of PD-1 and low levels of CD127 expression. J Virol. 2007; 81: 2545-53.

10. Watanabe T, Bertoletti A, Tanoto TA. PD-1/PD-L1 pathway and T-cell exhaustion in chronic hepatitis virus infection. J Viral Hepat. 2010; 17: 453-8.

11. Sumida K, Shimoda S, Iwasaka S, Hisamoto S, Kawanaka H, Akahoshi T, et al. Characteristics of splenic CD8 ${ }^{+} \mathrm{T}$ cell exhaustion in patients with hepatitis C. Clin Exp Immunol. 2013; 174: 172-8.

12. Rossille D, Gressieer M, Damotte D, Maucort-Boulch D, Pangault C, Semana G, et al.; Groupe Ouest-Est des Leucémies et Autres Maladies du Sang. High level of soluble programmed cell death ligand 1 in blood impacts overall survival in aggressive diffuse large B-cell lymphoma: results from a French multicenter clinical trial. Leukemia. 2014; 28: 2567-75.

13. Chen L. Co-inhibitory molecules of the B7-CD28 family in the control of T-cell immunity. Nat Rev Immunol. 2004; 4: 336-47.

14. Atanackovic D, Luetkens T, Kroger N. Coinhibitory molecule PD-1 as a potential target for the immunotherapy of multiple melanoma. Leukemia. 2014; 28: 993-1000.

15. Finkelmeier F, Canli Ö, Tal A, Pleli T, Trojan J, Schmidt M, et al. High levels of the soluble programmed death-ligand (sPD-L1) identify hepatocellular carcinoma patients with a poor prognosis. Eur J Cancer. 2016; 59: 152-9.

16. Chen Y, Wang Q, Shi B, Xu P, Hu Z, Bai L, et al. Development of a sandwich ELISA for evaluating soluble PD-L1 (CD274) in human sera of different ages as well as supernatants of PD-L1+ cell lines. Cytokine. 2011; 56: 231-8.

17. Wang L, Wang H, Chen $H$, Wang WD, Chen XQ, Geng QR, et al. Serum levels of soluble programmed death ligand 1 predict treatment response and progression free survival in multiple myeloma. Oncotarget. 2015; 6: 41228-36.

18. Frigola X, Inman BA, Lohse CM, Krco CJ, Cheville JC, Thompson RH, et al. Identification of a soluble form of B7-H1 that retains immunosuppressive activity and is associated with aggressive renal cell carcinoma. Clin Cancer Res. 2011; 17: 1915-23.

19. Reddy KR, Zeuzem S, Zoulim F, Weiland O, Horban A, Stanciu C, et al. Simeprevir versus telaprevir with peginterferon and ribavirin in previous null or partial responders with chronic hepatitis $C$ virus genotype 1 infection (ATTAIN): a 410andomized, double-blind, non-inferiority phase 3 trial. Lancet Infect Dis. 2015; 15: 27-35.

20. Jacobson IM, McHutchison JG, Dusheiko G, Di Bisceglie AM, Reddy KR, Bzowej NH, et al.; ADVANCE Study Team. Telaprevir for previously untreated chronic hepatitis C virus infection. N Engl J Med. 2011; 364: 2405-16.

21. Zeuzem S, Andreone P, Pol S, Lawitz E, Diago M, Roberts S, et al.; REALIZE Study Team. Telaprevir for retreatment of HCV infection. N Engl J Med. 2011; 364: $2417-28$

22. Fried MW, Buti M, Dore GJ, Flisiak R, Ferenci P, Jacobson I, et al. Once-daily simeprevir (TMC435) with pegylated interferon and ribavirin in treatment-naïve genotype 1 hepatitis C: the randomized PILLAR study. Hepatology. 2013; 58: 1918-29.

23. Jacobson IM, Dore GI, Foster GR, Fried MW, Radu M, Rafalsky VV, et al Simeprevir with pegylated interferon alfa 2 a plus ribavirin in treatment- $\odot$ patients with chronic hepatitis C virus genotype 1 infection (QUEST-1): a phase 3, randomized, double-blind, placebo-controlled trial. Lancet. 2014; 384: 403-13.

24. Akuta N, Suzuki F, Sezaki H, Suzuki Y, Hosaka T, Someya T, et al. Association of amino acid substitution pattern in core protein of hepatitis $C$ virus genotype b high viral load and non-virological response to interferon-ribavirin combination therapy. Intervirology. 2005; 48: 372-80.

25. Kuang DM, Zhao Q, Peng C, Xu J, Zhang JP, Wu C, et al. Activated monocytes in peritumoral stroma of hepatocellular carcinoma foster immune privilege and disease progression through PD-L1. J Exp Med. 2009; 206: 1327-37.

26. Gao Q, Wang XY, Qiu SJ, Yamato I, Sho M, Nakajima Y, et al. Overexpression of PD-L1 significantly associates with tumor aggressiveness and postoperative recurrence in human hepatocellular carcinoma. Clin Cancer Res. 2009; 15: $971-9$ 
27. Cariani E, Pilli M, Zerbini A, Rota C, Olivani A, Pelosi G, et al. Immunological and molecular correlates of disease recurrence after liver resection for hepatocellular carcinoma. PloS One. 2012; 7: e32493.

28. Yanaba K, Hayashi M, Yoshihara Y, Nakagawa H. Serum levels of soluble programmed death-1 and programmed death ligand-1 in systemic sclerosis: Association with extent of skin sclerosis. J Dermatol. 2016; 43: 954-7.

29. Shi B, Du X, Wang $\mathrm{Q}$, Chen $\mathrm{Y}$, Zhang $X$. Increased PD-1 on CD4(+)CD28(-) T cell and soluble PD-1 ligand-1 in patients with T2DM: association with atherosclerotic macrovascular diseases. Metabolism. 2013; 62: 778-85.

30. Mühlbauer M, Fleck M, Schütz C, Weiss T, Froh M, Blank C, et al. PD-L1 is induced in hepatocytes by viral infection and by interferon-alpha and -gamma and mediates T cell apoptosis. J Hepatol. 2006; 45: 520-8.

31. Bertoletti A, D’Elious MM, Boni C, De Carli M, Zignego AL, Durazzo M, et al. Different cytokine profiles of intrahepatic $\mathrm{T}$ cells in chronic hepatitis $\mathrm{B}$ and hepatitis C virus infections. Gastroenterology. 1997; 112: 1193-9.

32. Kanda T. Interferon-free treatment for HCV-infected patients with decompensated cirrhosis. Hepatol Int. 2017; 11: 38-44. 